\title{
The African Open Access portal as a Covid-19 information hub
}

UNISA Open Access Webinar | October 21, 2020

Priscilla Mensah [ORCID: 0000-0002-0134-5495] Umar Ahmad [ORCID: 0000-0002-3216-5171] Luke Okelo [ORCID: 0000-0002-5994-6517] 


\section{The African OA platform}

AfricArXiv is a community-led platform for African scientists of any discipline to present their research findings and connect with other researchers.

Repository partners

$$
\text { Znodo PubPub }
$$

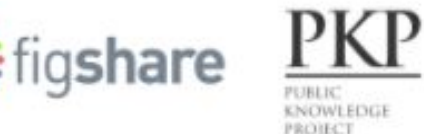



these repositories

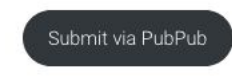

\section{PubPub}

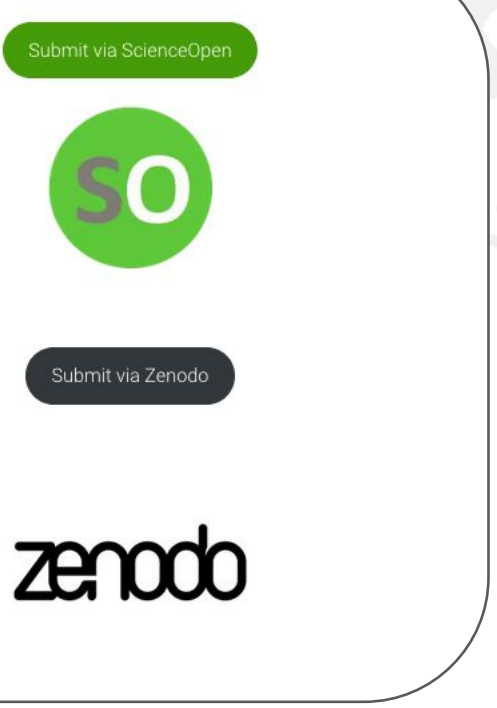




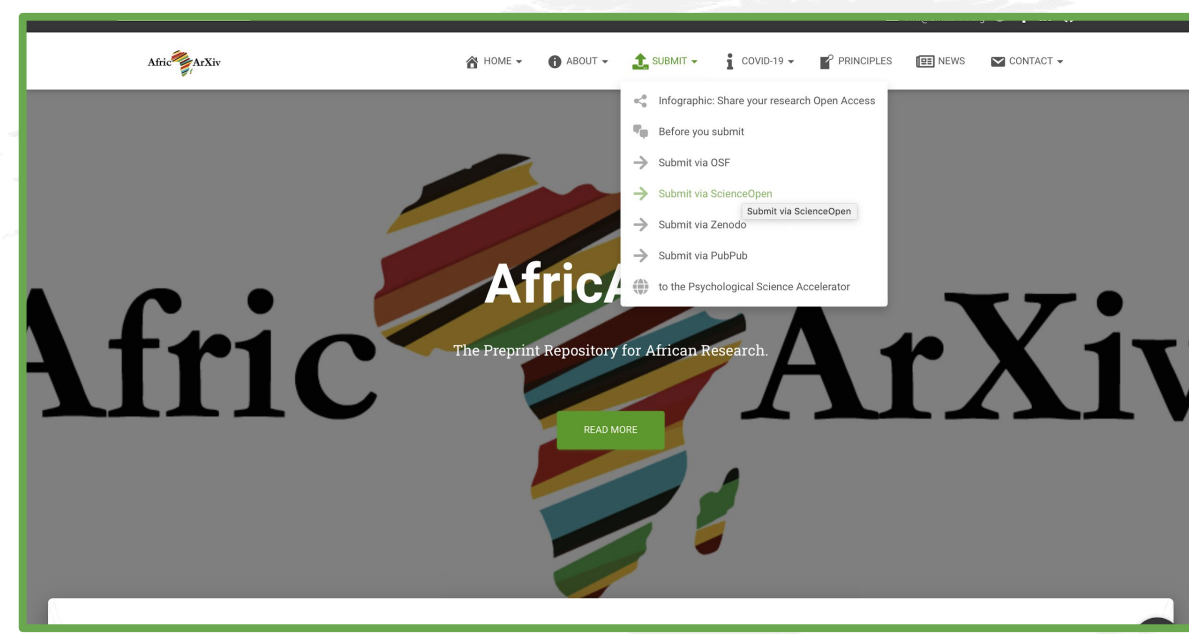

scienceOPEN.com

Afric

research+publishing network

ArXiv

ScienceOPEN.com

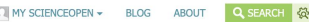
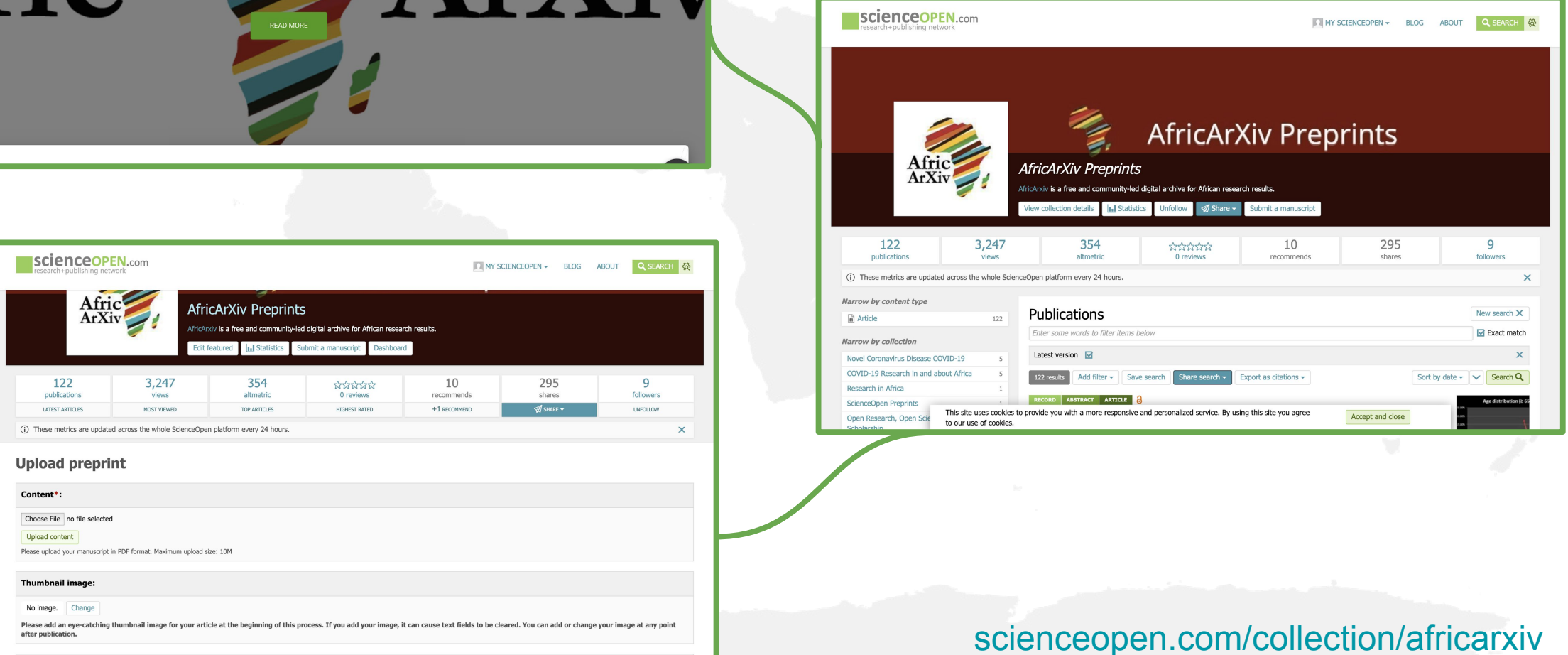

scienceopen.com/collection/africarxiv 

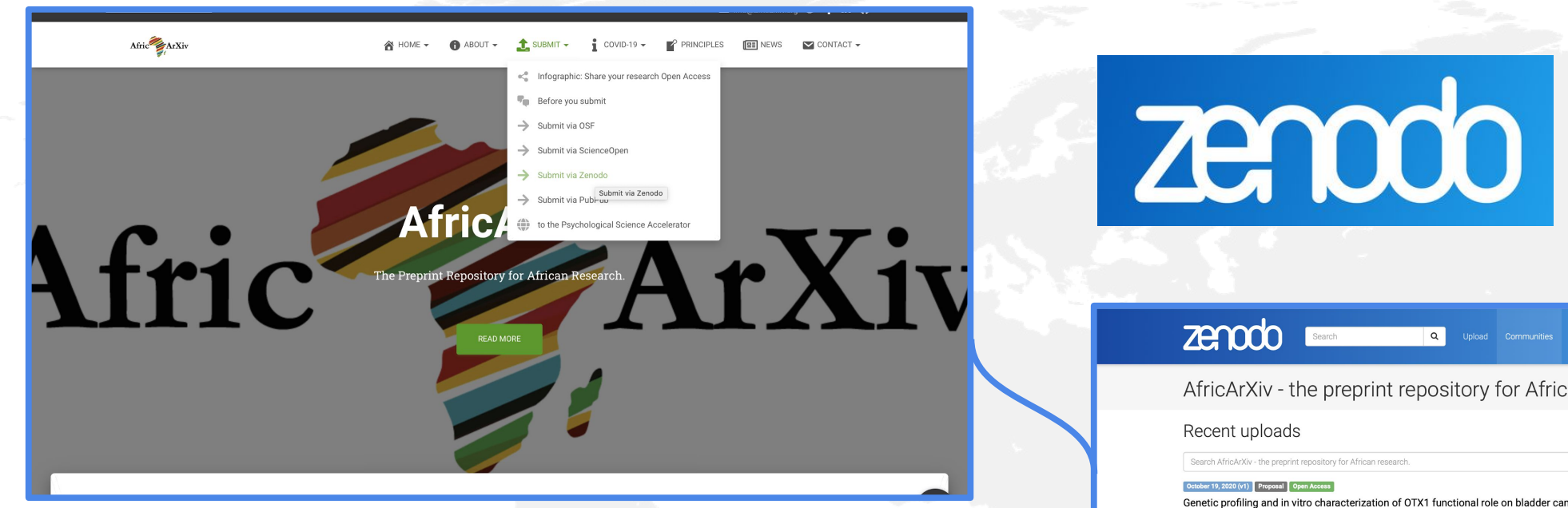

Afric ArXiv

\section{Zenodo}

a

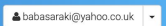

AfricArXiv - the preprint repository for African research.

Recent uploads

\pm New upload

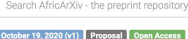

Genetic proffling and in vitro characterization of OTX 1 functionat

Stem cells

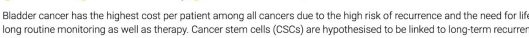

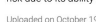

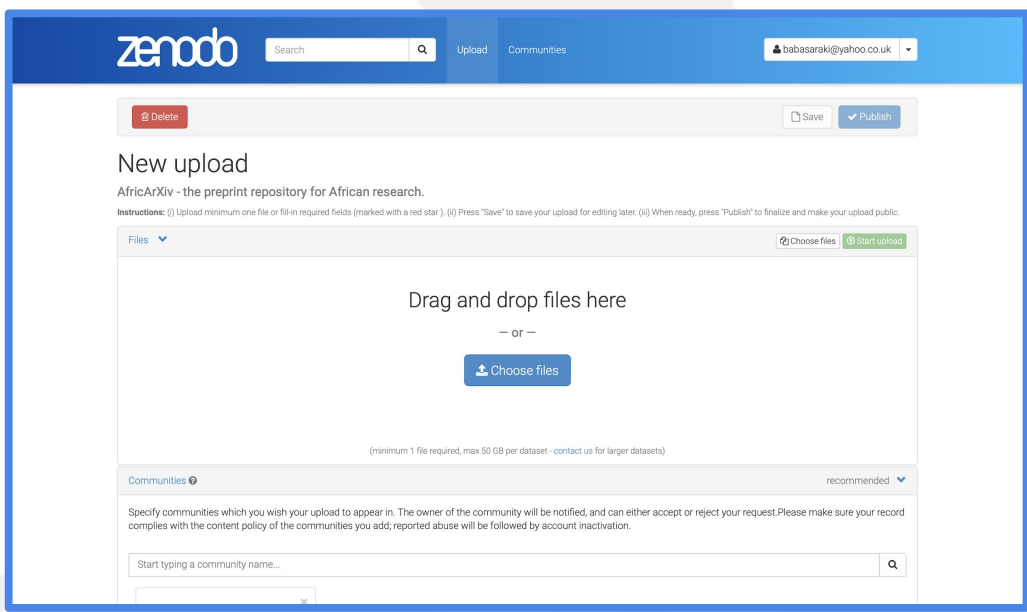

(2)

Antiproliferative and Chemotherapeutics Effects of Nigerian Honey and

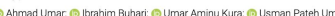

(1)

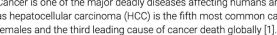

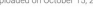

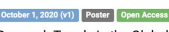

$$
\text { Afric ArXiv }
$$

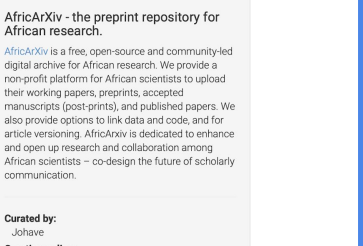

Drag and drop files here

\pm Choose files

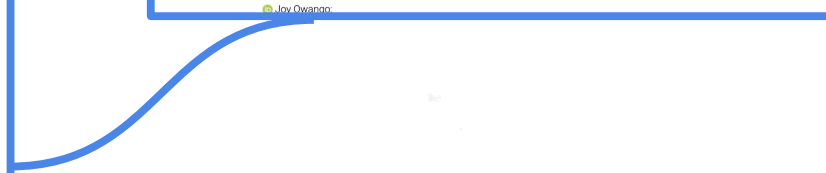

zenodo.org/communities/africarxiv/ 


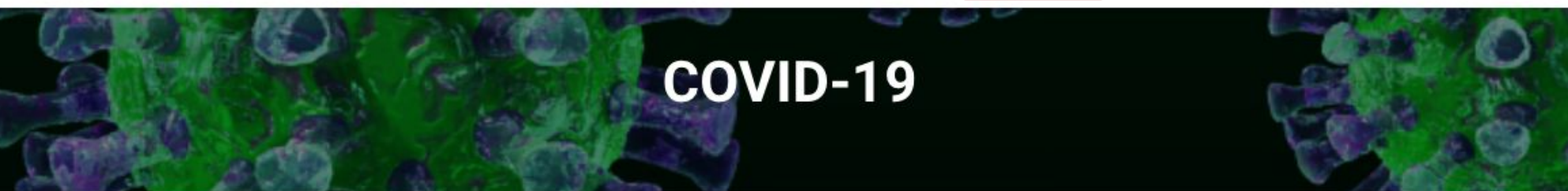

Resources, ideas, and guidelines around the COVID-19 pandemic in Africa

Q Q\&A around COVID-19 in regional African languages

Multilingual COVID-19 Information Videos

$\square$ ScienceOpen collection on 'COVID-19' and 'Africa' (ext. url)

Harnessing the Open Science infrastructure for an efficient African response to COVID-19 [preprint]

F African Science Literacy on COVID-19

回 Lessons learned from the Ebola outbreak 


\section{COVID-19 Research in and about Africa}

A collection of COVID-19 research artides dealing specifically with challenges and achievements on the African continent.

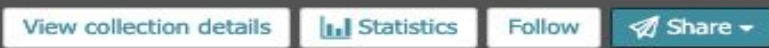

\begin{tabular}{|c|c|c|c|c|c|c|}
\hline $\begin{array}{c}379 \\
\text { publications }\end{array}$ & $\underset{\text { views }}{11,708}$ & $\begin{array}{c}12,425 \\
\text { altmetric }\end{array}$ & 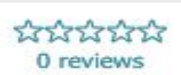 & $\frac{3}{\text { recommends }}$ & $\begin{array}{c}16 \\
\text { shares }\end{array}$ & $\begin{array}{c}7 \\
\text { followers }\end{array}$ \\
\hline
\end{tabular}

Narrow by content type

$$
\text { [A] Article }
$$

Narrow by collection

Novel Coronavirus Disease COVID-19

Wiley: Novel Coronavirus COVID-19

UCL: Covid-19 Research

Pan African Medical Journal:

COVID-19

MDPI: Coronavirus

\section{Publications}

Enter some words to filter items below

379 results Add filter - Save search

Share search -

Export as citations Sort by Altmetric score $-\checkmark$ Search Q

\section{\begin{tabular}{|l|l|l|l|l|l|l|} 
RECORD & ABSTRACT & ARTICLE & a
\end{tabular}}

Decreased Influenza Activity During the COVID-19 Pandemic -

United States, Australia, Chile, and South Africa, 2020

Sonja Olsen, Eduardo Azziz-Baumgartner, Alicia Budd, Lynnette Brammer, Sheena Sullivan, 3 more... (2020)

After recognition of widespread community transmission of SARS-CoV-2, the virus that causes coronavirus disease 2019 (COVID-19), by mid- to late Februar $\backsim$ Show more

New search $X$

$\square$ Exact match

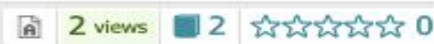
scienceopen.com/collection/COVID19 Africa 


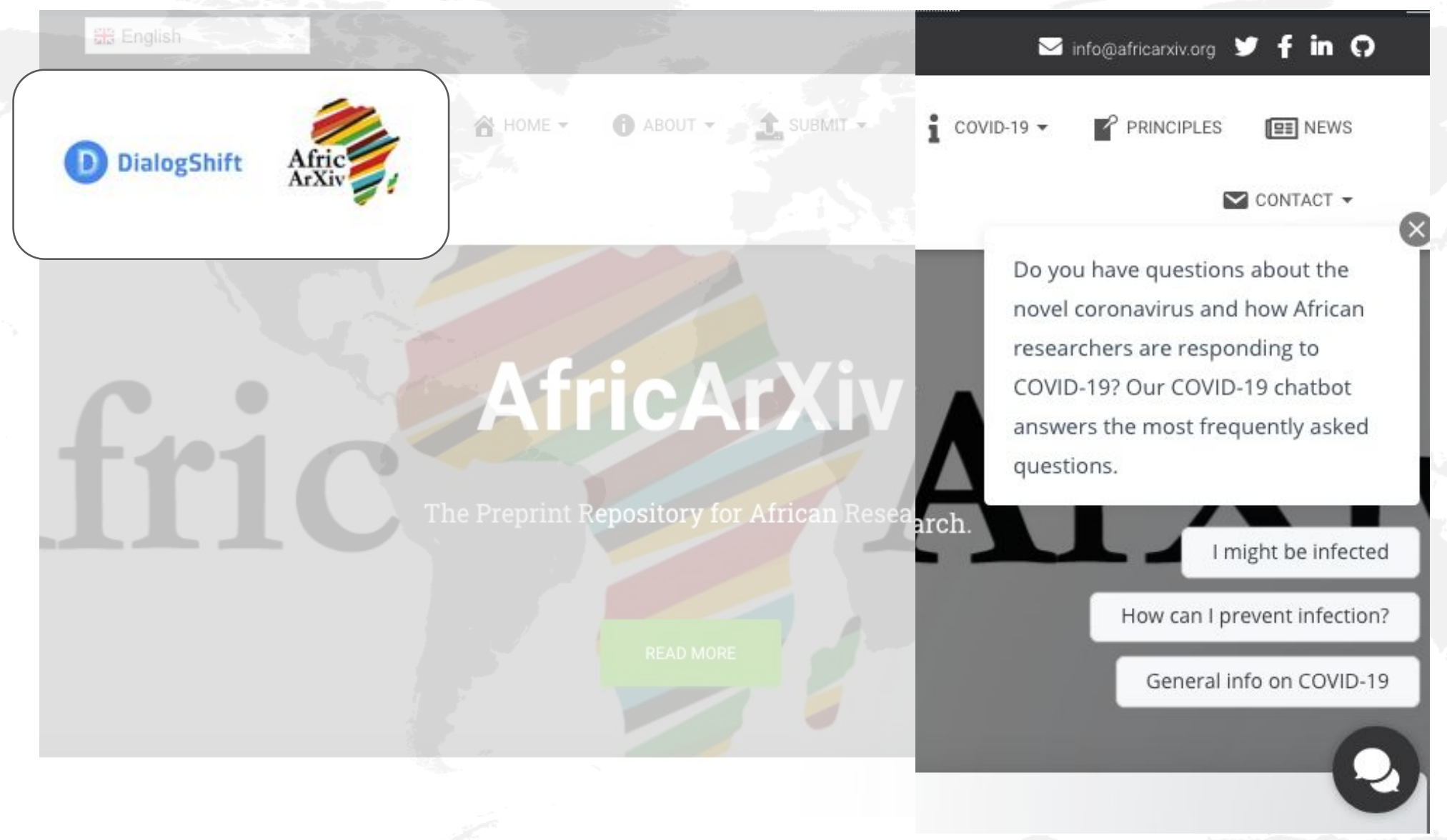




\section{Data Flow Diagram (DFD)}

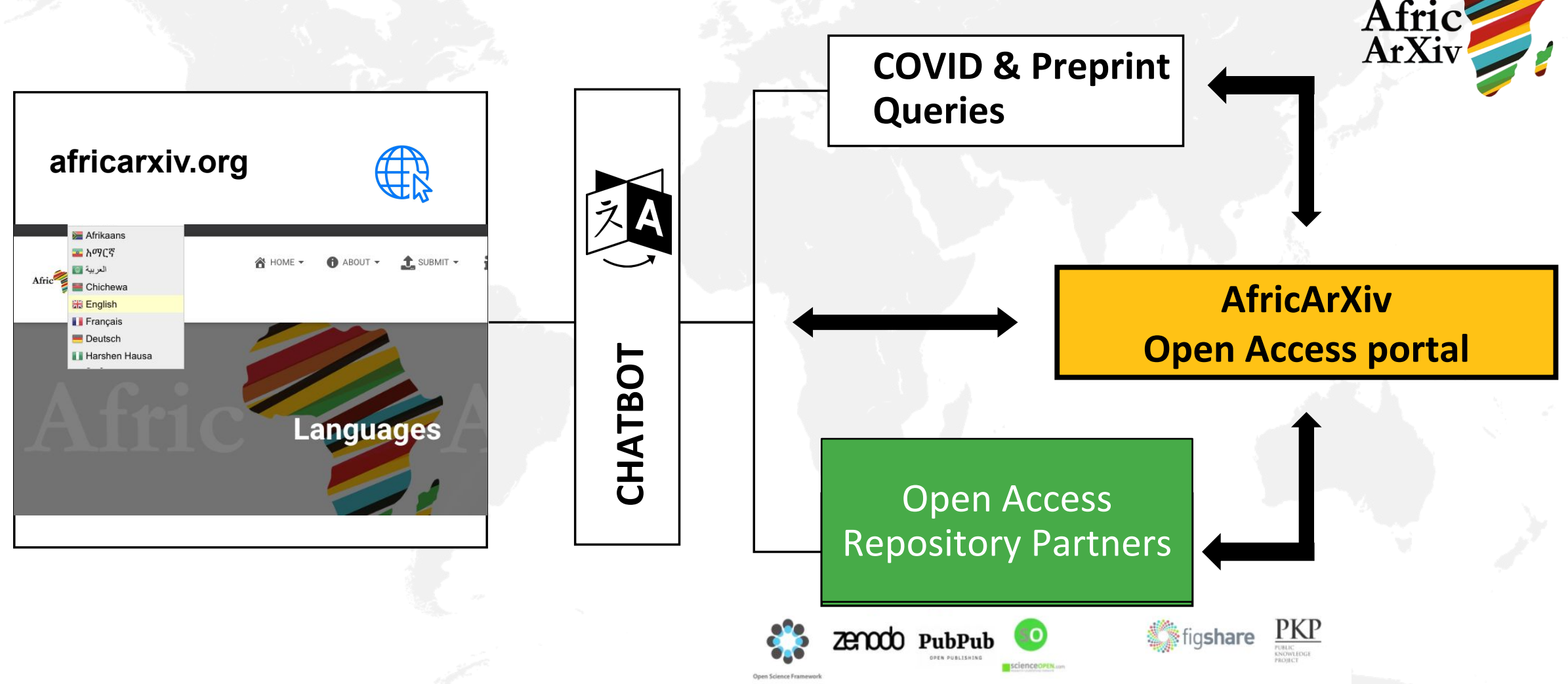




\section{Chatbot analysis}

Since May 2020, the top 6 queries (of $n=208$ ) included (but not limited to) :-

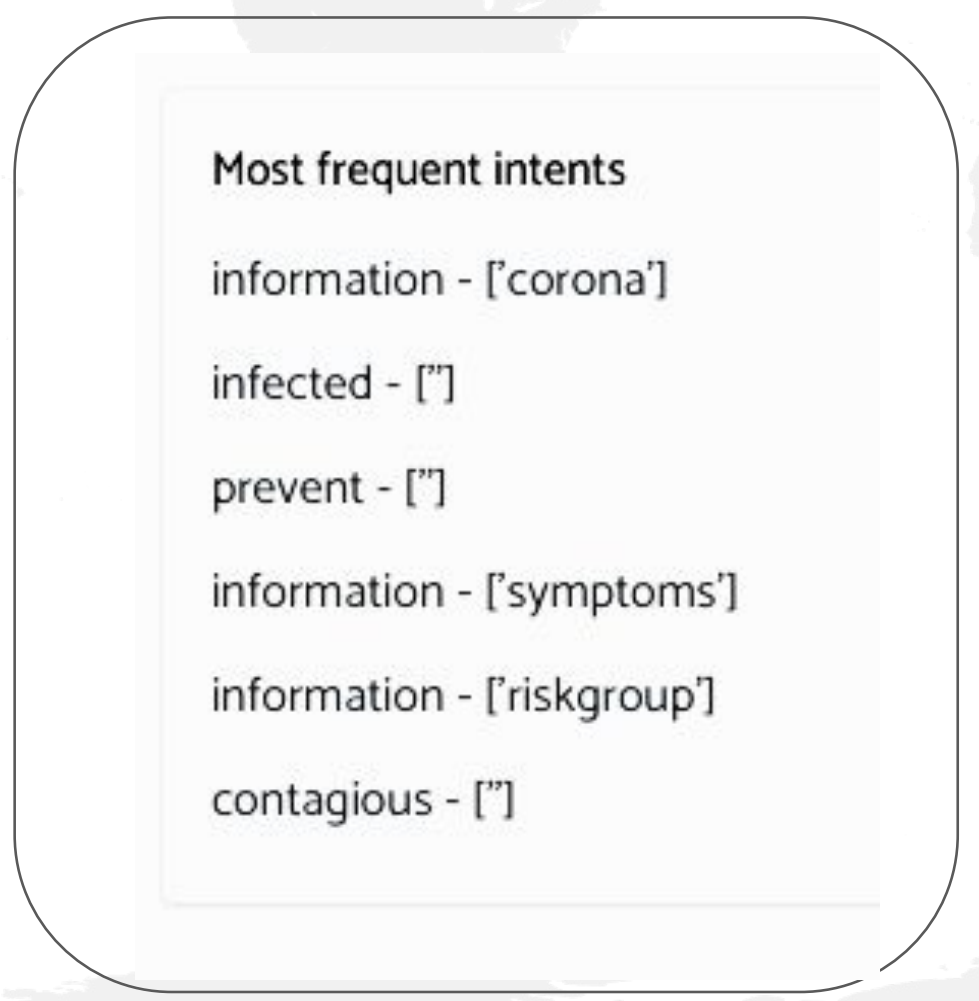

Such data analyses can benefit organizations in both health and academia to gain better insights into conversations African Scholars is having around the novel COVID-19 outbreak. 


\section{African Scholar?}

Let us know how we can support you
Other notable insights from our datasets include:

1. $43.3 \%$ of users accessed our chatbot using smartphones

portatric ArXiv

2. $56.7 \%$ of users accessed our chatbot platform using a computer, desktop or laptop

Scientists and our research from and about Africa are becoming more widely discoverable

\section{Thank You}

\section{Any questions?}

